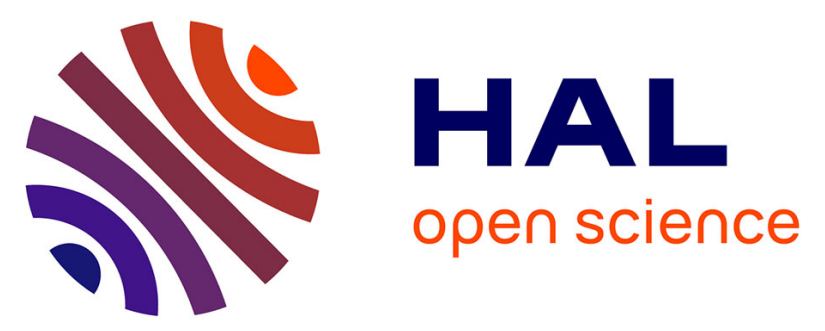

\title{
Psycho-social factors related to obesity and their associations with socioeconomic characteristics: the RECORD study
}

\author{
Sonsoles Fuentes, Ruben Brondeel, Manuel Franco, Xisca Sureda, Pierre \\ Traissac, Laura Kate Cleary, Basile Chaix
}

\section{To cite this version:}

Sonsoles Fuentes, Ruben Brondeel, Manuel Franco, Xisca Sureda, Pierre Traissac, et al.. Psychosocial factors related to obesity and their associations with socioeconomic characteristics: the RECORD study. Eating and Weight Disorders - Studies on Anorexia, Bulimia and Obesity, In press, 10.1007/s40519-018-00638-9 . hal-02178987

\section{HAL Id: hal-02178987 \\ https://hal.sorbonne-universite.fr/hal-02178987}

Submitted on 10 Jul 2019

HAL is a multi-disciplinary open access archive for the deposit and dissemination of scientific research documents, whether they are published or not. The documents may come from teaching and research institutions in France or abroad, or from public or private research centers.
L'archive ouverte pluridisciplinaire HAL, est destinée au dépôt et à la diffusion de documents scientifiques de niveau recherche, publiés ou non, émanant des établissements d'enseignement et de recherche français ou étrangers, des laboratoires publics ou privés. 
Psycho-social factors related to obesity and their associations with socioeconomic characteristics: the RECORD Study

Sonsoles Fuentes ${ }^{1,2}$, Ruben Brondeel ${ }^{1,2}$, Manuel Franco ${ }^{3,4}$, Xisca Sureda ${ }^{3}$, Pierre Traissac ${ }^{5}$, Laura Kate Cleary ${ }^{1,2}$, and Basile Chaix ${ }^{1,2}$

1 Inserm, UMR-S 1136, Pierre Louis Institute of Epidemiology and Public Health, Nemesis team, Paris, France;

2 Sorbonne Universités, UPMC Univ Paris 06, UMR-S 1136, Pierre Louis Institute of Epidemiology and Public Health, Nemesis team, Paris, France;

3 Social and Cardiovascular Epidemiology Research Group, School of Medicine, University of Alcalá. Alcalá de Henares, Madrid, Spain;

4 Department of Epidemiology, Johns Hopkins Bloomberg School of Public Health, Baltimore, MD, US;

5 IRD (Institut de Recherche pour le Développement), UMR NUTRIPASS, IRD-UMSupAgro, Montpellier, France ;

KEYWORDS: Obesity; socioeconomic status; childhood; residential neighborhood; Psychosocial factors; depression.

RUNNING TITLE: Obesity-related Psycho-social factors

CONTACT INFO:

Sonsoles Fuentes, UMR-S 1136, Faculté de Médecine Saint-Antoine, 27 rue Chaligny, 75020

Paris

sfuegut@gmail.com

WORD COUNT: 3709 


\section{ABSTRACT}

Objectives: We aimed to describe the main psycho-social factors related to obesity in an adult population and to develop a unified construct (psycho-social profiles), in order to explore the associations between socioeconomic characteristics and these psycho-social profiles.

Methods: In its second wave, the RECORD Study assessed 6460 participants aged 30-79 years in the Paris region between 2011 and 2014. Factor analyses followed by cluster analysis were applied to identify psycho-social profiles related to obesity. The two psycho-social profiles were: adverse profile - negative body image, underestimation of the impact of weight in quality of life, low weight-related self-efficacy, and weight-related external locus of control; and favorable profile - positive body image, high self-efficacy, and internal locus of control. The relationship between three socioeconomic dimensions - current socioeconomic status, childhood socioeconomic status, and neighborhood education status - and psychosocial profiles was assessed through binomial logistic regression adjusted for age, gender, depression, living alone, and weight status.

Results: Contrary to hypotheses, there were no associations between socioeconomic characteristics and obesity-related psycho-social profiles after adjustment for body mass index. Depressive symptoms (OR: 2.21, 95\% CI: 2.70, 4.04) and being a female (3.31, 95\%CI: 2.70, 4.40) were associated with an adverse psycho-social profile.

Conclusions: Psycho-social profiles could help to understand the multifactorial nature of the determinants of obesity. 


\section{Introduction}

Obesity and overweight have become a major public health concern in the last few decades. They are important risk factors for different non-communicable diseases such as cardiovascular diseases, diabetes, various cancers, and musculoskeletal disorders [1]. Bidirectional associations have also been found with psychological disorders like depression [2].

One important upstream factor affecting the prevalence of obesity in high and middle income countries is the socioeconomic status of people [3]. The prevalence of obesity is higher among people with only primary school education compared to people with tertiary education [4,5]. This inverse relationship has been also described for the level of income [3]. Recent research has suggested that socioeconomic deprivation during childhood is an important predictor of adult weight status [6]. Finally, people living in deprived neighborhoods are more likely to have obesity than those living in less deprived areas [7].

A number of researchers have proposed a theoretical framework to explain the association of socioeconomic deprivation and poor health outcomes such as obesity [8]. Deprived individuals, or people living in deprived environments, are more frequently exposed to stressful experiences and have fewer resources to overcome them. This stress has an impact on psycho-social factors which then influence the adoption or maintenance of healthy behaviors. Psycho-social factors are defined as individual characteristics, learned through exposure to the social environment, and influencing individual's behaviors [9]

Various studies have analyzed the most common psycho-social factors related to obesity, especially in weight-loss and weight-maintenance programs, such as self-efficacy (the confidence in one's own ability to achieve intended results), body perception, body satisfaction, and locus of control (degree to which people believe that they have control over outcomes in their lives, as opposed to external forces beyond their control) [10-12]. 
However, the studies assessing relationships between socioeconomic characteristics and psycho-social factors related to obesity have yielded inconsistent results. High levels of certain advantageous psycho-social factors like self-efficacy are less frequently present among individuals with low socioeconomic status [13-15], while others like body satisfaction are less frequently present among individuals with high socioeconomic status [16]. Since psycho-social factors are usually correlated, some authors have suggested that it is inappropriate to study obesity-related psycho-social factors independently from each other, and that a tool (e.g., an overall profile) combining various such factors should be developed to assess the overall impact of this family of mechanisms [10].

This study aims to compose a psycho-social construct based on relevant psycho-social factors, in order to assess its relation with socioeconomic characteristics, using data from a large epidemiological cohort of adults living in the Paris metropolitan area of France. More specifically, our objectives were: (i) to describe relevant obesity-related psycho-social factors in our population; (ii) to examine whether these psycho-social factors could be aggregated into one construct through the development of obesity-related psycho-social profiles; and (iii) to explore the associations between socioeconomic characteristics and these psycho-social profiles.

Our main research hypothesis was that individuals with the most deprived individual socioeconomic characteristics and/or those living in the most deprived neighborhoods would be more likely to have adverse obesity-related psycho-social profiles (i.e., that can be hypothesized to promote obesity). 


\section{Methods}

\section{Study population}

The Residential Environment and Coronary Heart Disease (RECORD) Cohort Study was established to investigate environmental determinants of territorial disparities in health in the Ile de France region, which includes the Paris metropolitan area [17]. The French National Health Insurance Scheme for Salaried Workers offers a free medical examination every 5 years to all working and retired employees and their families. The RECORD Study recruited participants from the people engaged in these preventive medical check-ups. Participants had to be aged 30-79 years in 2007-2008 and to reside in one of 10 (out of 20) administrative divisions of Paris or 111 other municipalities of the region. These divisions or municipalities were chosen a priori in order to include socioeconomically advantaged and disadvantaged neighborhoods, with over-representation of disadvantaged districts, as well as urban and suburban areas. In addition to the health checkup, participants completed questionnaires related to their socio-demographic status, health behavior, family and personal medical history, and psychological characteristics.

The French Data Protection Authority approved the study protocol. There have been two cohort waves so far, the first wave between 2007 and 2008 and the second wave between 2011 and 2014. This study was based on the data from the second wave including 6460 participants. The exclusion criteria were as follows: to be a pregnant woman $(n=12)$, to have not answered to one or more questions from the RECORD questionnaire related to psychosocial factors or socioeconomic characteristics $(n=1593)$ and to have incomplete data on the characteristics of their neighborhood $(n=336)$. The final study population was composed by 4519 individuals.

\section{Psycho-social factors and psycho-social profiles}


The RECORD questionnaire was structured in the following parts: demographic and socioeconomic characteristics, self-reported health information, psychological health evaluation (QD2A depression questionnaire and perceived stress scale), self-reported experience in the residential neighborhood and health related behavior/psychological, cognitive and attitudinal characteristics. In this last part of the questionnaire, different items on psycho-social factors related to body weight perceptions and values and attitudes related to weight and weight control behaviors [17]. Further details on these items are provided in the Appendix Table 1. Three steps were followed to compose the Psycho-social construct 'Psycho-social profiles': explanatory factor analysis, confirmatory factor analysis and cluster analysis.

First, an exploratory factor analysis to identify the most relevant psycho-social factors was run based on the 24 items coded from the answers of the participants to the part of the questionnaire on health related behavior/psychological, cognitive and attitudinal characteristics [18]. An oblique rotation was used since cognitive/psychological factors are expected to be correlated [19]. Only factors with eigenvalues above 1 and having more than one item with an item-loading equal to or higher than 0.32 , were kept for the confirmatory factor analysis. After, the retain model was validated using confirmatory factor analysis, the correlations between factors were analyzed, and a score for each psycho-social factors was obtained through least squares regression. Third, a unique construct combining factors, referred to as psycho-social profiles, was defined through hierarchical cluster analysis (Figure 1). Ward's method was applied to the standardized psycho-social factor scores to identify two main psycho-social profiles: favorable and adverse [20].

\section{Individual socioeconomic factors}

As it was previously described, a part of the RECORD questionnaire was dedicated to participant's socioeconomic characteristics, with 13 items (described in detail in Appendix 
Table 2). An explanatory factor analysis followed by a confirmatory factor analysis was performed on these 13 items, to assess the most relevant individual socioeconomic factors. Two main socioeconomic factors were identified. The first factor was current socioeconomic status, based on six items: education level, household income, owning a secondary residence, owning a house/flat put in hiring, having savings over $25000 €$, and being able to raise funds for an urgent expense. The second factor, economic status in childhood, was based on three items retrospectively asked for the childhood period: parents' ownership of a car, parents' ownership of a house, and parents' financial strain. The resulting factor scores for each of the two individual socioeconomic factor were calculated by least squares regression and were then after divided into quartiles: very low status (first quartile), low status (second quartile), high status (third quartile), and very high status (fourth quartile, used as the reference category).

For the psycho-social and socioeconomic variables, the psych, lavaan, and stats packages from the R software (R3.3.0, 2016) were used to perform exploratory factor analysis, confirmatory factor analysis, and hierarchical cluster analysis.

\section{Neighborhood socioeconomic level}

The residential address of the participants was collected and geocoded using the VERITAS web mapping application. As a proxy for the socioeconomic level of the residential neighborhood, individually geocoded data from the 2010 French National Census were used to assess the proportion of residents aged 20 years or over with upper tertiary education inside a 1000 m street-network buffer defined around each individual's residential address [21]. This continuous variable was divided into quartiles, with the very high education level (fourth quartile) used as the reference category. 


\section{Other variables}

During the medical examination, a nurse measured participants' height and weight. Body Mass Index (BMI) was calculated as the ratio of weight $(\mathrm{kg})$ to the square of height $\left(\mathrm{m}^{2}\right)$. Three weight status categories were defined based on individual's BMI: not overweight (BMI $\left.<25 \mathrm{~kg} / \mathrm{m}^{2}\right)$, overweight $\left(25 \mathrm{~kg} / \mathrm{m}^{2} \leq\right.$ BMI $\left.<30 \mathrm{~kg} / \mathrm{m}^{2}\right)$ and obesity $\left(\right.$ BMI $\left.\geq 30 \mathrm{~kg} / \mathrm{m}^{2}\right)$ [22]. Depression was assessed through the validated QD2A questionnaire, include in the RECORD questionnaire [23,24]. The QD2A is composed of 14 items related to possible depressive symptoms (e.g. "I am disappointed and disgusted with myself," "I'm sad these days," "I feel hopeless about the future"). Individuals with scores above 7 are considered to have depressive symptoms (no depression as the reference category). Other variables included in the analysis were: age (as a continuous variable); gender (male as the reference category); and cohabitation status as a binary variable (living alone, and living with a partner as the reference category.

\section{Statistical analysis}

A descriptive analysis of the study population, including a description by psycho-social profile, was performed. Differences between the adverse and the favorable psycho-social profiles were assessed by a Kruskal-Wallis test for continuous variables and by a Fisher's exact test for categorical variables.

Since the outcome variable 'psycho-social profile' was a binary variable (Favorable profile vs Adverse profile), to assess its relationship with socioeconomic characteristics (current socioeconomic status, economic status in childhood and neighborhood socioeconomic level), binomial logistic regression was run. The logistic regression was also adjusted by gender, age, cohabitation status, presence of depressive symptoms and weight status. Interactions terms between socioeconomic variables (current socioeconomic status, economic status in childhood and neighborhood socioeconomic level) as well as interaction term between gender 
and depression were analyzed. The predictive value of the final logistic model was tested with three different methods: Hosmer-Lemeshow test, sensitivity and specificity analysis, and ROC curves. Regression analyses were performed with Stata version 12.0 (StatCorp LP, College Station, TX, USA)"

\section{Results}

The characteristics of the final study population $(n=4519)$ are summarized in Table 1 . Mean age was 53.3 years and $69.0 \%$ of the participants were men. Around $45 \%$ of individuals had a tertiary education and only $4.7 \%$ reported regular financial strain. The mean household income per consumption unit in the household was 1899 euros per month and the percentage of participants who were employed was $67.1 \%$. Half of the final population had overweight and around $21 \%$ of them had obesity.

\section{Psycho-social factors. Factor analysis}

Results of the exploratory factor analysis are shown in Table 2. Five psycho-social factors were identified, explaining $69 \%$ of the variance. The first factor was labelled weight-related self-efficacy, and included items related to the perceived ability to perform actions to control or to lose weight. The second factor was labelled weight-locus of control and included items measuring whether participants felt that individuals are responsible for their own weight. The third factor was underrate impact of weight on QoL (Quality of Life), including items related to the differences between participants' self-reported weight and the weight above which they felt less fit or the weight they believed would have negative consequences for their health. Two factors associated with body image were identified. The factor labelled weight dissatisfaction included items measuring the difference between reported weight and perceived ideal or acceptable weight. The factor labelled negative perceptions of body included items measuring the individual's evaluation of his/her weight status or his/her waist circumference. The internal consistency of each factor was assessed with the Cronbach Alpha 
coefficient $(\alpha \geq 0.7)$. Confirmatory factor analysis was then run to obtain a five factor model (see Table 3). In this model weight-related self-efficacy was negatively correlated with underrate impact of weight on QoL, weight dissatisfaction, and negative perceptions of body. A strong positive correlation, higher than 0.7 , was observed between weight dissatisfaction and negative perceptions of body.

\section{Psycho-social profiles. Cluster analysis}

Based on the factor scores obtained through the confirmatory factor analysis model, two psycho-social profiles were observed in the hierarchical cluster analysis: an adverse $(\mathrm{n}=818)$ and a favorable $(\mathrm{n}=4037)$ psycho-social profile. In the assessment of the dendogram, these two profiles were clearly differentiated. The favorable psycho-social profile had a higher mean for weight-related self-efficacy $($ mean $=0.15)$ than the adverse psycho-social profile $($ mean $=-0.70)$ but a lower mean for the other psycho-social factors: weight dissatisfaction $(-$ 0.24 vs 1.17), negative perceptions of body (-0.17 vs 0.82$)$, underrate impact of weight on QoL (-0.19 vs 0.93), and weight-related locus of control (-0.01 vs 0.04) (see Table 1).

The current socioeconomic status and the economic status in childhood also differed between the favorable and the adverse psycho-social profiles. There were higher percentages of people with a high current socioeconomic status and with a high economic status in childhood among people with a favorable psycho-social profile than among those with an adverse profile, while the opposite was true for the percentages of people with a low current and childhood socioeconomic statuses. Almost $10 \%$ of people with adverse psycho-social profile presented depressive symptoms, more than double of the percentage in the favorable Psycho-social profile group. The percentage of individuals with obesity in the adverse psycho-social profile was $38.5 \%$, whereas this percentage was only of $5.5 \%$ in the favorable profile.

Socioeconomic variables and psycho-social profiles. Binomial logistic regression 
When controlling for the other covariates (and especially for the very strong association between BMI and psycho-social profile), current socioeconomic status, economic status in childhood, and educational level in the neighborhood were not associated with the odds of an adverse psycho-social profile (see Table 4). The odds of having an adverse psycho-social profile were more than three times higher for women compared to men (95\% CI: $2.70,4.04)$. The odds of having an adverse psycho-social profile were two times higher among individuals with depressive symptoms than among non-depressed individuals (95\% CI: 1.51, 3.24). As expected, participants with overweight had 8 times higher odds and participants with obesity 40 times higher odds of having an adverse psycho-social profile.

\section{Discussion}

Psycho-social factors related to obesity could help to understand the relationship between socioeconomic deprivation and obesity. Through factor analysis, five main psycho-social factors were identified among a study population of adults living in Paris. Deriving two clusters of individuals based on their psycho-social factors allowed us to examine the predictors of having an adverse obesity-related psycho-social profile as a unified construct. This study was not able to confirm that three different socioeconomic dimensions (current socioeconomic status, economic status in childhood, and neighborhood education) were associated with psycho-social profiles. However, associations were found between depression and psycho-social profiles.

The five psycho-social factors identified through factor analysis were coherent with the psycho-social factors related to obesity previously described in other studies. The first factor, self-efficacy, was defined by Albert Bandura in the context of the Social Cognitive Theory as "people's beliefs about their capabilities to produce designated levels of performances that

exercise influence over events that affect their lives" [9]. Self-efficacy is a key factor in maintaining adequate physical activity and eating behaviors over a long period, and a strong 
predictor of sustained weight loss after weight control treatments [12]. The second factor found in exploratory factor analysis was weight-related locus of control. Originating in the work of Julian Rotter, this construct refers to an individual's belief in the amount of control that people have on their weight $[25,26]$. Individuals with internal weight-related locus of control, or those who relate body weight to people's own actions and not to external influences, have a lower risk of being overweight [27]. On the opposite, those who believe that people have a natural weight and that obesity cannot be controlled through behavioral changes are less likely to lose weight through weight control programs [10]. A literature review conducted in 2015 found that underrating the impact of weight on QoL is one of the most important psycho-social factors related to obesity and it was very relevant for the prediction of success in weight loss and maintenance programs [10].

Body image, or individuals' concept of their own bodies, is a complex construct mainly composed by two factors that were assessed in this study: body perception and weight satisfaction [28]. Negative body perceptions are associated with weight management failure and treatment discontinuation in weight loss programs [10]. Weight dissatisfaction has been described as a risk factor for different eating disorders [29-32].

These two factors were strongly correlated in the five-factor model obtained through confirmatory factor analysis. In this model, there was an inverse correlation between selfefficacy and the two factors related to body image, which has been described before in studies on other populations including young adults or individuals enrolled in weight-loss programs [33]. Other psycho-social factors such as self-regulation [34] and social support [11] were not considered in this particular analysis.

In the theoretical framework proposed by Matthews et al, the psycho-social factors play a mediating role in the relation between socioeconomic deprivation and negative health outcomes [8]. Different studies have described the association of socioeconomic 
characteristics with the psycho-social factors observed in our study. A large body of literature has examined the negative impact of socioeconomic deprivation on self-efficacy $[13,14]$. Regarding the relationship between socioeconomic deprivation and other psycho-social factors, a cross-sectional study conducted in Germany found the percentage of reported weight dissatisfaction to be higher among individuals with high socioeconomic status [16]. Another study based on data from the Health Survey for England (HSE) observed that underrating the impact of weight on QoL was more common among overweight individuals with a low socioeconomic status than among overweight individuals with a higher socioeconomic status [35]. Antenatal and childhood economic deprivation was an important predictor of external locus of control at eighteen years of age in a British cohort study [15].

On the opposite, this study was not able to confirm the relationship between socioeconomic dimensions and psycho-social profiles as a unified construct. These results can be explained because previous studies only assessed one socioeconomic dimension at time, while this study assessed three different socioeconomic dimensions: current socioeconomic status, economic status in childhood, and education status in the residential neighborhood. Another possible explanation is the divergent directions of the relations between the factors composing the Psycho-social construct and the socioeconomic characteristics, some factors are more common in low socioeconomic status while others are more common in high socioeconomic status.

We documented an association between gender and psycho-social profiles. This gender disparity has been described before: women are more likely to report low self-efficacy and higher body dissatisfaction than men [16]. The observed relationship between having depressive symptoms and showing an adverse psycho-social profile is consistent with previous studies concluding that depressive disorders are related to poor body image [36], low self-efficacy [37], and to an external locus of control [15]. Some authors have suggested that 
psycho-social factors could play a mediating role in the association between obesity and depression [38]. Three potential pathways are described for this association: behavioral (functional impairment or unhealthy dieting), cognitive (poor body image and low selfefficacy), and social (weight-based stigma). This framework offers an opportunity to develop interventions based on psycho-social factors in individuals with obesity and overweight not only to improve physical health but also to prevent the development of mental disorders.

\section{Strengths and limitations}

A limitation of the study was the large proportion of observations with missing values (32\%). Excluded individuals were more socioeconomically deprived than those included in the study population. This could have led to underestimate the relationship between socioeconomic characteristics and psycho-social profiles. Also, because the recruitment strategy of the study favored the inclusion of salaried, formerly salaried, or retired workers and their families speaking French, certain deprived groups like immigrants may have been omitted. Also, there is a risk of "recall bias", especially regarding the economic status in childhood. The external validity of the results could also be affected by the fact that a high majority of the participants were male. However, it should be emphasized that our sample is more heterogeneous than other studies related to psycho-social factors where study populations were composed only of women or individuals engaged in weight-loss programs [10].

This study has important strengths. To understand socioeconomic inequalities in health, it is necessary to rely on an eco-social appraisal by combining individual and ecosystem levels with a life-course perspective [39]. While most of the studies only focused on present individual socioeconomic dimensions (such as current household income) [40], three different socioeconomic dimensions were evaluated in this study: current socioeconomic status, economic status in childhood, and education status in the residential neighborhood. Another strength of our study is the large sample size that was available, compared to most of the 
studies on psycho-social factors related to obesity were small samples were used [12]. Many studies on obesity used self-reported weight status, which has many limitations, such as overestimation of weight for younger adults or underestimation for people with overweight [41]. In this study, BMI was calculated based on height and weight measures assessed by healthcare professionals. Regardless of the measurement method, however, BMI and its cutoffs for overweight and obesity have been criticized as tools to evaluate the weight status in certain populations like Asiatic or older adults [42,43]. Finally, a clear strength of the present study is its use of factor analysis and cluster analysis to derive obesity-related psycho-social profiles from a rich questionnaire.

\section{Conclusion}

In this study, a comprehensive methodology was applied to assess the relationship between socioeconomic characteristics and psycho-social factors in a population of adults living in the Paris metropolitan region. To our knowledge this is the first time that a combination of exploratory factor analysis, confirmatory factor analysis and cluster analysis is applied to develop a psycho-social construct based on psycho-social factors related to obesity. Another contribution of this study is to assess three different dimensions of socioeconomic characteristics: current socioeconomic status, economic status in childhood, and education status in the residential neighborhood. In future research on psycho-social factors associated with obesity and socioeconomic characteristics, it is necessary to develop validated and shared instruments to measure psycho-social factors. While a separate focus on each psychosocial factor could be interesting, the study of integrated psycho-social profiles introduced in the present study should not be neglected. This approach can help to understand the multifactorial nature of the determinants of obesity. 


\section{Compliance with ethical standards}

\section{Funding}

The RECORD Study was funded by the Institute for Public Health Research (IReSP); the National Institute for Prevention and Health Education (INPES); the National Institute of Public Health Surveillance (InVS); the French Ministries of Research and Health; the National Health Insurance Office for Salaried Workers (CNAM-TS); the Ile-de-France Regional Health Agency (ARS); the Ile-de-France Regional Council; the National Research Agency (ANR); the City of Paris; and the Ile-de-France Youth, Sports, and Social Cohesion Regional Direction (DRJSCS).

\section{Conflict of interest}

On behalf of all authors, the corresponding author states that there is no conflict of interest.

\section{Ethical approval}

All procedures performed in the study were in accordance with the ethical standards of the French national research committee and with the 1964 Helsinki declaration and its later amendments. Informed consent was obtained from all individual participants included in the study.

The French Data Protection Authority has approved the study protocol.

\section{Informed consent}

Informed consent was obtained from all individual participants included in the study 


\section{References}

1. Collaboration NRF (2016) Trends in adult body-mass index in 200 countries from 1975 to 2014: a pooled analysis of 1698 population-based measurement studies with 19.2 million participants. Lancet (London, England) 387 (10026):1377-1396. doi:10.1016/s0140-6736(16)30054-x

2. Preiss K, Brennan L, Clarke D (2013) A systematic review of variables associated with the relationship between obesity and depression. Obesity reviews : an official journal of the International Association for the Study of Obesity 14 (11):906-918. doi:10.1111/obr.12052

3. Herzog B, Lacruz ME, Haerting J, Hartwig S, Tiller D, Medenwald D, Vogt S, Thorand B, Holle R, Bachlechner U, Boeing H, Merz B, Nothlings U, Schlesinger S, Schipf S, Ittermann T, Aumann N, Schienkiewitz A, Haftenberger M, Greiser KH, Neamat-Allah J, Katzke V, Kluttig A (2016) Socioeconomic status and anthropometric changes-A meta-analytic approach from seven German cohorts. Obesity (Silver Spring, Md) 24 (3):710-718. doi:10.1002/oby.21366

4. Cohen AK, Rai M, Rehkopf DH, Abrams B (2013) Educational attainment and obesity: a systematic review. Obesity reviews : an official journal of the International Association for the Study of Obesity 14 (12):989-1005. doi:10.1111/obr.12062

5. Chaix B, Bean K, Daniel M, Zenk SN, Kestens Y, Charreire H, Leal C, Thomas F, Karusisi N, Weber C, Oppert JM, Simon C, Merlo J, Pannier B (2012) Associations of supermarket characteristics with weight status and body fat: a multilevel analysis of individuals within supermarkets (RECORD study). PLoS One 7 (4):e32908. doi:10.1371/journal.pone.0032908

6. Giskes K, van Lenthe FJ, Turrell G, Kamphuis CB, Brug J, Mackenbach JP (2008) Socioeconomic position at different stages of the life course and its influence on body weight and weight gain in adulthood: a longitudinal study with 13-year follow-up. Obesity (Silver Spring, Md) 16 (6):1377-1381. doi:10.1038/oby.2008.54

7. Leal C, Bean K, Thomas F, Chaix B (2011) Are associations between neighborhood socioeconomic characteristics and body mass index or waist circumference based on model extrapolations? Epidemiology 22 (5):694-703. doi:10.1097/EDE.0b013e3182257784

8. Matthews KA, Gallo LC, Taylor SE (2010) Are Psycho-social factors mediators of socioeconomic status and health connections? A progress report and blueprint for the future. Annals of the New York Academy of Sciences 1186:146-173. doi:10.1111/j.1749-6632.2009.05332.x

9. Bandura A (2001) Social cognitive theory: An agentic perspective. Annual review of psychology 52 (1):1-26

10. Lazzeretti L, Rotella F, Pala L, Rotella CM (2015) Assessment of psychological predictors of weight loss: How and what for? World journal of psychiatry 5 (1):56-67. doi:10.5498/wjp.v5.i1.56

11. Teixeira PJ, Going SB, Sardinha LB, Lohman TG (2005) A review of Psycho-social pre-treatment predictors of weight control. Obesity reviews : an official journal of the International Association for the Study of Obesity 6 (1):43-65. doi:10.1111/j.1467-789X.2005.00166.x

12. Palmeira AL, Teixeira PJ, Branco TL, Martins SS, Minderico CS, Barata JT, Serpa SO, Sardinha LB (2007) Predicting short-term weight loss using four leading health behavior change theories. The international journal of behavioral nutrition and physical activity 4:14. doi:10.1186/1479-5868-4-14 
13. Kamimura A, Jess A, Trinh HN, Aguilera G, Nourian MM, Assasnik N, Ashby J (2017) Food Insecurity Associated with Self-Efficacy and Acculturation. Population health management 20 (1):66-73. doi:10.1089/pop.2015.0179

14. Guntzviller LM, King AJ, Jensen JD, Davis LA (2017) Self-Efficacy, Health Literacy, and Nutrition and Exercise Behaviors in a Low-Income, Hispanic Population. Journal of immigrant and minority health 19 (2):489493. doi:10.1007/s10903-016-0384-4

15. Culpin I, Stapinski L, Miles OB, Araya R, Joinson C (2015) Exposure to socioeconomic adversity in early life and risk of depression at 18 years: The mediating role of locus of control. Journal of affective disorders 183:269-278. doi:10.1016/j.jad.2015.05.030

16. von Lengerke T, Mielck A (2012) Body weight dissatisfaction by socioeconomic status among obese, preobese and normal weight women and men: results of the cross-sectional KORA Augsburg S4 population survey. BMC public health 12:342. doi:10.1186/1471-2458-12-342

17. Chaix B, Kestens Y, Bean K, Leal C, Karusisi N, Meghiref K, Burban J, Fon Sing M, Perchoux C, Thomas F, Merlo J, Pannier B (2012) Cohort profile: residential and non-residential environments, individual activity spaces and cardiovascular risk factors and diseases--the RECORD Cohort Study. International journal of epidemiology 41 (5):1283-1292. doi:10.1093/ije/dyr107

18. Yong AG, Pearce S (2013) A beginner's guide to factor analysis: Focusing on exploratory factor analysis. Tutorials in quantitative methods for psychology 9 (2):79-94

19. Santos NC, Costa PS, Amorim L, Moreira PS, Cunha P, Cotter J, Sousa N (2015) Exploring the factor structure of neurocognitive measures in older individuals. PLoS One 10 (4):e0124229. doi:10.1371/journal.pone.0124229

20. Everitt B, Landau S, Leese M (2001) Cluster analysis, vol 33. Quality and Quantity

21. Brondeel R, Weill A, Thomas F, Chaix B (2014) Use of healthcare services in the residence and workplace neighbourhood: the effect of spatial accessibility to healthcare services. Health \& place 30:127-133. doi:10.1016/j.healthplace.2014.09.004

22. Organization WHO (2000) Obesity: preventing and managing the global epidemic. Report of a WHO consultation. World Health Organ Tech Rep Ser 894:i-xii, 1-253

23. Pichot P (1984) Un questionnaire d'auto-évaluation de la symptomatologie dépressive, le Questionnaire QD2: I. Construction, structure factorielle et propriétés métrologiques. Revue de psychologie appliquée

24. Annequin M, Weill A, Thomas F, Chaix B (2015) Environmental and individual characteristics associated with depressive disorders and mental health care use. Ann Epidemiol 25 (8):605-612. doi:10.1016/j.annepidem.2015.02.002

25. Saltzer EB (1982) The weight locus of control (WLOC) scale: a specific measure for obesity research. Journal of personality assessment 46 (6):620-628. doi:10.1207/s15327752jpa4606_11

26. Rotter JB (1966) Generalized expectancies for internal versus external control of reinforcement. Psychol Monogr 80 (1):1-28

27. Kapadia MZ, Gaston A, Van Blyderveen S, Schmidt L, Beyene J, McDonald H, McDonald SD (2015) Psychological antecedents of excess gestational weight gain: a systematic review. BMC Pregnancy Childbirth 15:107. doi:10.1186/s12884-015-0535-y 
28. Chao HL (2015) Body image change in obese and overweight persons enrolled in weight loss intervention programs: a systematic review and meta-analysis. PLoS One 10 (5):e0124036. doi:10.1371/journal.pone.0124036

29. Wardle J, Waller J, Rapoport L (2001) Body dissatisfaction and binge eating in obese women: the role of restraint and depression. Obesity research 9 (12):778-787. doi:10.1038/oby.2001.107

30. Forrester-Knauss C, Zemp Stutz E (2012) Gender differences in disordered eating and weight dissatisfaction in Swiss adults: which factors matter? BMC public health 12:809. doi:10.1186/1471-2458-12-809

31. Zarychta K, Chan CKY, Kruk M, Luszczynska A (2018) Body satisfaction and body weight in under- and healthy-weight adolescents: mediating effects of restrictive dieting, healthy and unhealthy food intake. Eat Weight Disord. doi:10.1007/s40519-018-0496-Z

32. Rukavina T, Pokrajac-Bulian A (2006) Thin-ideal internalization, body dissatisfaction and symptoms of eating disorders in Croatian adolescent girls. Eat Weight Disord 11 (1):31-37

33. Annesi JJ, Mareno N (2015) Improvement in emotional eating associated with an enhanced body image in obese women: mediation by weight-management treatments' effects on self-efficacy to resist emotional cues to eating. Journal of advanced nursing 71 (12):2923-2935. doi:10.1111/jan.12766

34. Anderson ES, Winett RA, Wojcik JR (2007) Self-regulation, self-efficacy, outcome expectations, and social support: social cognitive theory and nutrition behavior. Annals of behavioral medicine 34 (3):304-312

35. Minet Kinge J, Morris S (2010) Socioeconomic variation in the impact of obesity on health-related quality of life. Social science \& medicine (1982) 71 (10):1864-1871. doi:10.1016/j.socscimed.2010.09.001

36. Manaf NA, Saravanan C, Zuhrah B (2016) The Prevalence and Inter-Relationship of Negative Body Image Perception, Depression and Susceptibility to Eating Disorders among Female Medical Undergraduate Students. Journal of clinical and diagnostic research : JCDR 10 (3):Vc01-vc04. doi:10.7860/jcdr/2016/16678.7341

37. Tahmassian K, Jalali Moghadam N (2011) Relationship between self-efficacy and symptoms of anxiety, depression, worry and social avoidance in a normal sample of students. Iranian journal of psychiatry and behavioral sciences 5 (2):91-98

38. Markowitz S, Friedman MA, Arent SM (2008) Understanding the relation between obesity and depression: causal mechanisms and implications for treatment. Clinical Psychology: Science and Practice 15 (1):1-20

39. Krieger N (2001) Theories for social epidemiology in the 21 st century: an ecosocial perspective. International journal of epidemiology 30 (4):668-677

40. Geyer S, Hemstrom O, Peter R, Vagero D (2006) Education, income, and occupational class cannot be used interchangeably in social epidemiology. Empirical evidence against a common practice. Journal of epidemiology and community health 60 (9):804-810. doi:10.1136/jech.2005.041319

41. Stommel M, Schoenborn CA (2009) Accuracy and usefulness of BMI measures based on self-reported weight and height: findings from the NHANES \& NHIS 2001-2006. BMC public health 9 (1):421. doi:10.1186/1471-2458-9-421

42. Barba C, Cavalli-Sforza T, Cutter J, Darnton-Hill I, Deurenberg P, Deurenberg-Yap M (2004) Appropriate body-mass index for Asian populations and its implications for policy and intervention strategies. Lancet (London, England) 363 (9403):157-163. doi:10.1016/s0140-6736(03)15268-3

43. Sergi G, Perissinotto E, Pisent C, Buja A, Maggi S, Coin A, Grigoletto F, Enzi G (2005) An adequate threshold for body mass index to detect underweight condition in elderly persons: the Italian Longitudinal Study 
on Aging (ILSA). The journals of gerontology Series A, Biological sciences and medical sciences 60 (7):866871 
Table 1. Descriptive information on the study population, overall and stratified by psycho-social profiles

\begin{tabular}{|c|c|c|c|}
\hline & All & $\begin{array}{c}\text { Favorable } \\
\text { profile }\end{array}$ & $\begin{array}{l}\text { Adverse } \\
\text { profile }\end{array}$ \\
\hline $\mathrm{n}$ & 4519 & 3771 & 748 \\
\hline Age, years, mean (SD) & $53.3(11,3)$ & $53.2(11.3)$ & $53.6(11.2)$ \\
\hline Sex (men), \% & 69.0 & 72.1 & 53.3 \\
\hline Living alone, \% & 18.2 & 17.7 & 20.9 \\
\hline \multicolumn{4}{|l|}{ Individual education, \% } \\
\hline No education & 3.8 & 3.8 & 3.7 \\
\hline Primary, lower secondary & 23.1 & 22.8 & 24.3 \\
\hline Higher secondary, lower tertiary & 27.8 & 27.4 & 30.1 \\
\hline Upper tertiary & 45.3 & 46.0 & 30.1 \\
\hline Employment (yes), \% & 67.1 & 67.8 & 63.9 \\
\hline $\begin{array}{l}\text { Household income per consumption unit, } \\
\text { euros, mean (SD) }\end{array}$ & $\begin{array}{r}1899.8 \\
(1138.3)\end{array}$ & $1929.0(1150.0)$ & $1752.9(1066.0)$ \\
\hline Financial strain, \% & 4.7 & 4.1 & 7.4 \\
\hline \multicolumn{4}{|l|}{ Current socioeconomic status ${ }^{c}, \%$} \\
\hline Very High (q4) & & 26.0 & 19.8 \\
\hline High (q3) & & 25.3 & 23.8 \\
\hline Low (q2) & & 25.1 & 24.5 \\
\hline Very low (q1) & & 23.6 & 32.0 \\
\hline \multicolumn{4}{|l|}{ Economic status in childhood ${ }^{\mathrm{d}}, \%$} \\
\hline Very High (q4) & & 25.6 & 21.9 \\
\hline High (q3) & & 25.3 & 23.7 \\
\hline Low (q2) & & 24.7 & 26.5 \\
\hline Very low (q1) & & 24.4 & 27.9 \\
\hline \multicolumn{4}{|l|}{ Education level in neighborhood ${ }^{\mathrm{e}}, \%$} \\
\hline Very High (q4) & & 25.5 & 22.3 \\
\hline High (q3) & & 25.1 & 24.6 \\
\hline Low (q2) & & 25.0 & 25.0 \\
\hline Very low (q1) & & 24.4 & 28.1 \\
\hline \multicolumn{4}{|l|}{ Psycho-social factor scores, mean (SD) } \\
\hline Weight dissatisfaction & $-0.0035(0,88)$ & $-0.2357(0.60)$ & $1.1673(1.12)$ \\
\hline Negative perceptions of body & $-0.0044(0.58)$ & $-0.1683(0.44)$ & $0.8217(0.52)$ \\
\hline Underrate impact of weight on $\mathrm{QoL}^{\mathrm{b}}$ & $-0.0037(0.84)$ & $-0.1895(0.67)$ & $0.9328(0.99)$ \\
\hline Weight-related locus of control & $-0.0002(0.64)$ & $-0.0091(0.64)$ & $0.0448(0.63)$ \\
\hline Weight-related self-efficacy & $0.0096(0.60)$ & $0.1483(0.48)$ & $-0.6902(0.64)$ \\
\hline Depression ${ }^{\mathrm{f}}$ (yes), $\%$ & 4.7 & 3.9 & 9.1 \\
\hline \multicolumn{4}{|l|}{ Weight status ${ }^{\mathrm{g}}, \%$} \\
\hline Not overweight & 49.0 & 56.2 & 12.8 \\
\hline Overweight & 40.1 & 38.4 & 48.7 \\
\hline Obesity & 10.9 & 5.5 & 38.5 \\
\hline
\end{tabular}

* pValue to assess the difference between favorable and adverse psycho-social profiles (Kruskal-Wallis test for continuous variables and Fisher exact test for categorical variables) lower than 0.05

${ }^{a}$ Proportion of residents aged $>20$ with an upper tertiary education in a $1 \mathrm{~km}$ individual buffer (Data source: French national census 2010)

${ }^{\mathrm{b}}$ Quality of life (QoL)

${ }^{\mathrm{c}}$ Current socioeconomic status based on six items: education level, household income, "to own a second home", "to be landlord/lady", "to have savings over 25000€" and "to be able to raise funds for an urgent expense"

"Economic status in childhood, was based on three items, "parents owned a car", "parents owned a house" and "parents reported financial strain"

e Proportion of residents aged > 15 with an upper tertiary education in a $1 \mathrm{~km}$ individual buffer (Data source: French national census 2010)

${ }^{f}$ Depression: based on QD2A-Pichot 13 items questionnaire; individuals with scores > 7 are considered depressed.

$\mathrm{g}$ Weight status based on Body Mass Index (BMI): Normal $\left(>25 \mathrm{Kg} / \mathrm{m}^{2}\right)$, Overweight $\left(\leq 25 \mathrm{Kg} / \mathrm{m}^{2}\right.$ and $>$ $\left.30 \mathrm{Kg} / \mathrm{m}^{2}\right)$ and Obesity $\left(\leq 30 \mathrm{Kg} / \mathrm{m}^{2}\right)$ 
Table 2. Results of exploratory factor analysis ${ }^{a}$ on items from RECORD $^{b}$ questionnaire related to psychosocial factors

Psycho-social factors

Eigen values

Proportion of variance

explained

Cronbach Alpha, 95\% CI

Items

$\begin{array}{ccccc}0.84 & 0.01 & 0.01 & 0.00 & -0.01 \\ 0.55 & 0.02 & -0.03 & -0.06 & -0.04 \\ 0.79 & 0.03 & 0.03 & 0.02 & 0.02 \\ -0.02 & & & & \\ & 0.86 & -0.01 & 0.04 & 0.00 \\ 0.00 & 0.80 & & & \\ & & 0.04 & -0.04 & 0.01\end{array}$

5. Difference between reported weight and weight above have negative consequences for health(standardized)

6. Perception of waist circumference

7. Perception of weight status

8. Difference between reported weight and ideal weight (standardized)

9. Difference between reported weight and maximum acceptable weight (standardized)

10. Each person is responsible of his/her own weight

11. Excessive weight is due

Self-
efficacy $\quad$\begin{tabular}{c}
$\begin{array}{c}\text { Underrate } \\
\text { Impact of } \\
\text { weight on } \\
\text { QoL }^{\mathbf{c}}\end{array}$ \\
\hline 1.63
\end{tabular}

Negative
perceptions of
body

Weight
dissatisfaction

0.15

0.75

0.82

$(0.72,0.77)$

$(0.79,0.86)$

$(0.76,0.84)$

0.15

0.14

0.91

$(0.87,0.94)$

$(0.65,0.74)$

Item-loadings to psycho-social Jolliffe factors

$$
0.80
$$

0.04

0.01

to a lack of effort

$\begin{array}{ccccc}0.00 & 0.03 & 0.74 & 0.01 & -0.01 \\ 0.03 & 0.03 & 0.87 & 0.04 & 0.01 \\ -0.01 & 0.15 & 0.17 & 0.69 & 0.00 \\ 0.02 & 0.13 & & & \\ & & 0.11 & 0.82 & -0.02 \\ 0.04 & 0.01 & 0.00 & & \\ & & & 0.02 & 0.65 \\ -0.02 & 0.00 & 0.00 & & \\ & & & -0.03 & 0.81\end{array}$

\footnotetext{
${ }^{a}$ Exploratory factor analysis - number of factors: 10 (only factors with eigen values above 1) ; rotation method: oblique-promax ; size of population: 4855. Fit indices: Root mean square error of approximation: $0.019,95 \%$ CI $(0.016,0.022)$; Tucker Lewis Index: 0.983; Bayesian Information Criterion: -459

${ }^{\mathrm{b}}$ The RECORD (Residential Environment and Coronary Heart Disease) included 24 items on psycho-social factors, but only those with item loadings to SCG-Factors higher than 0.32 were represented in the table

${ }^{c}$ Quality of life (Impact of weight on QoL)
} 
Table 3. Results of confirmatory factor analysis ${ }^{\text {a }}$ : Five psycho-social factors model ${ }^{\mathbf{b}}$, variances and correlation matrix

\begin{tabular}{|c|c|c|c|c|c|c|}
\hline \multirow[b]{3}{*}{ Self-efficacy } & \multirow[t]{2}{*}{ Variance } & \multicolumn{5}{|c|}{ Correlation coefficients } \\
\hline & & $\begin{array}{l}\text { Self- } \\
\text { efficacy }\end{array}$ & $\begin{array}{l}\text { Weight } \\
\text { locus of } \\
\text { control }\end{array}$ & $\begin{array}{l}\text { Underrate impact } \\
\text { of weight on } \mathrm{QoL}^{\mathrm{c}}\end{array}$ & $\begin{array}{l}\text { Negative } \\
\text { perceptions } \\
\text { of body }\end{array}$ & $\begin{array}{l}\text { Weight } \\
\text { dissatisfaction }\end{array}$ \\
\hline & 0.44 & 1 & 0.14 & -0.18 & -0.28 & -0.21 \\
\hline $\begin{array}{l}\text { Weight locus of } \\
\text { control }\end{array}$ & 0.56 & & 1 & 0.12 & 0.11 & 0,10 \\
\hline $\begin{array}{l}\text { Underrate impact } \\
\text { of weight on QoL }\end{array}$ & 0.81 & & & 1 & 0,60 & 0.73 \\
\hline $\begin{array}{l}\text { Negative } \\
\text { perceptions of } \\
\text { body }\end{array}$ & 0.41 & & & & 1 & 0.78 \\
\hline $\begin{array}{l}\text { Weight } \\
\text { dissatisfaction }\end{array}$ & 0.84 & & & & & 1 \\
\hline $\begin{array}{l}{ }^{\mathrm{a}} \text { Confirmatory fact } \\
\text { questionnaire related } \\
{ }^{\mathrm{b}} \text { Fit indices (degre } \\
95 \% \mathrm{CI}(0.040,0.048 \\
{ }^{\mathrm{c}} \text { Quality of Life }(\mathrm{Qo}\end{array}$ & $\begin{array}{l}\mathrm{r} \text { analysis b } \\
\text { to psycho-so } \\
\text { of freedom } \\
\text { Tucker Lew } \\
\text { ) }\end{array}$ & $\begin{array}{l}\text { ed on the } \\
\text { al factors. } \\
\text { 34) chi-Squ } \\
\text { Index } 0.97\end{array}$ & $\begin{array}{l}\text { ults of exp } \\
\text { d } 350.39\end{array}$ & $\begin{array}{l}\text { ratory factor analysis } \\
\text { ot mean square error }\end{array}$ & $\begin{array}{l}\text { on items from } \\
\text { of approximat }\end{array}$ & $\begin{array}{l}\text { RECORD } \\
\text { on: } \quad 0.044\end{array}$ \\
\hline
\end{tabular}


Table 4. Associations between three socioeconomic dimensions and having an adverse psycho-social profile ${ }^{\text {a }}$

\begin{tabular}{|c|c|c|c|}
\hline & OR & $95 \% \mathrm{CI}$ & $\mathrm{p}$ Value \\
\hline \multicolumn{4}{|c|}{ Current socioeconomic status ${ }^{b}$} \\
\hline Very high (Q4) & ref & & \\
\hline High (Q3) & 1.10 & $(0.83,1.47)$ & 0.500 \\
\hline Low (Q2) & 0.91 & $(0.67,1.24)$ & 0.556 \\
\hline Very low (Q1) & 0.89 & $(0.64,1.24)$ & 0.493 \\
\hline \multicolumn{4}{|c|}{ Childhood economic status $^{c}$} \\
\hline Very high (Q4) & ref & & \\
\hline High (Q3) & 0.86 & $(0.64,1.14)$ & 0.284 \\
\hline Low (Q2) & 0.83 & $(0.62,1.12)$ & 0.221 \\
\hline Very low (Q1) & 0.85 & $(0.61,1.16)$ & 0.303 \\
\hline \multicolumn{4}{|c|}{ Neighborhood education status ${ }^{d}$} \\
\hline Very high (Q4) & ref & & \\
\hline High (Q3) & 0.95 & $(0.73,1.23)$ & 0.692 \\
\hline Low (Q2) & 0.93 & $(0.72,1.22)$ & 0.606 \\
\hline Very low (Q1) & 0.80 & $(0.61,1.05)$ & 0.111 \\
\hline Living alone (yes) & 1.03 & $(0.81,1.30)$ & 0.821 \\
\hline Depression $^{\mathrm{e}}$ (yes) & 2.21 & $(1.51,3.24)$ & $<0.001$ \\
\hline Gender (women) & 3.31 & $(2.70,4.04)$ & $<0.001$ \\
\hline Age & 0.99 & $(0.98,1.00)$ & 0.017 \\
\hline \multicolumn{4}{|l|}{ Weight status ${ }^{\mathrm{f}}$} \\
\hline Not overweight & ref & & \\
\hline Overweight & 8.14 & $(6.33,10.46)$ & $<0.001$ \\
\hline Obesity & 40.31 & $(30.00,54.18)$ & $<0.001$ \\
\hline
\end{tabular}

a Adverse profile characterized by low self-efficacy, poor body image, external weight locus of control and underestimation of impact of weight in quality of life. Favorable (reference) profile characterized by high self-efficacy, good body image, internal weight locus of control and moderate underestimation of impact of weight in quality of life

${ }^{\mathrm{b}}$ Current socioeconomic status based on six items: education level, household income, "to own a second home", "to be landlord/lady", "to have savings over $25000 €$ " and "to be able to raise funds for an urgent expense"

"Economic status in childhood, was based on three items, "parents owned a car", "parents owned a house" and "parents reported financial strain"

d Proportion of residents aged $>15$ with an upper tertiary education in a $1 \mathrm{~km}$ individual buffer (Data source: French national census 2010)

${ }^{\mathrm{e}}$ Depression: based on QD2A-Pichot 13 items questionnaire; individuals with scores $>7$ are considered depressed.

${ }^{\mathrm{f}}$ Weight status based on Body Mass Index (BMI): Normal (> $25 \mathrm{Kg} / \mathrm{m}^{2}$ ), Overweight $\left(\leq 25 \mathrm{Kg} / \mathrm{m}^{2}\right.$ and $\left.>30 \mathrm{Kg} / \mathrm{m}^{2}\right)$ and Obesity $\left(\leq 30 \mathrm{Kg} / \mathrm{m}^{2}\right)$ 


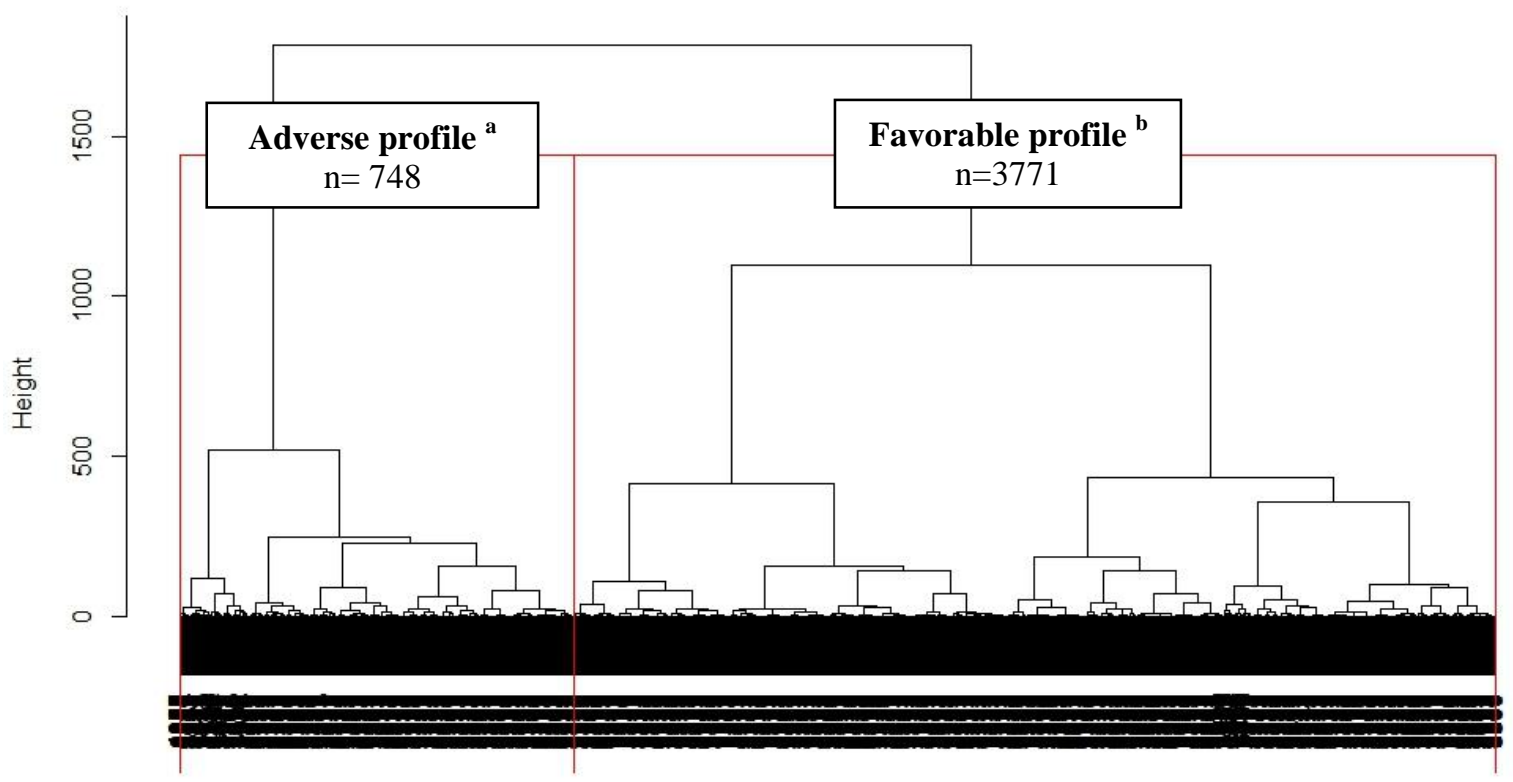

Figure 1. Dendrogram: Hierarchical cluster analysis of psychosocial factors using Ward's method based on Euclidean distances between observations.

a. Adverse profile characterized by low self-efficacy, poor body image, external weight locus of control and underestimation of impact of weight in quality of life. b. Favorable profile characterized by high self-efficacy, good body image, internal weight locus of control and moderate underestimation of impact of weight in quality of life 